\title{
A NECESSIDADE DO CONHECIMENTO TECNOLÓGICO PARA O ACESSO À INFORMAÇÃO QUALIFICADA NO CO- MÉRCIO DE DIAMANTES LAPIDADOS DO MERCADO DE CONSUMO BRASILEIRO
}

\section{THE NEED FOR TECHNOLOGICAL KNOWLEDGE TO ACCESS QUALIFIED INFORMATION IN THE TRADE OF BRAZILIAN CONSUMPTED DIAMONDS: THE CONCRETE CASE OF APPLICATION OF INFRARED INFRASTRUCTURE SPECTROSCOPY}

\author{
Maurício da Silva Borges" \\ Simone Patrícia Aranha da Paz"* \\ DENNIS VERBICARO ****
}

\section{RESUMO}

O trabalho tem por objetivo discutir a relação consumerista dos diamantes lapidados no que diz respeito ao fornecimento pelo fornecedor das informações completas e necessárias acerca da natureza de tal produto: natural, melhorado, artificial ou imitado. Demonstrarse-á a dificuldade de obtenção de informações através de análises de seis amostras de gemas inorgânicas, obtidas através do método de Espectroscopia de Infravermelho Por Transformada de Fourier (FTIR), pelo equipamento o Nicolet 6700 Spectrometer (Thermo Electron Corporation), provando a complexidade da relação por exigir equipamentos tecnológicos que normalmente são acessíveis aos grandes laboratórios, universidades e a pesquisadores de grande treinamento prático e especializado conhecimento técnico. Neste contexto, é evidente a fragilidade do consumidor em função

\begin{abstract}
This paper discuss the consumerist relation of lapidated diamonds with regard to the provision of complete and necessary information about the nature of the product: natural, improved, artificial or imitation. It will be demonstrated the difficulty of obtaining information through analyzes of six inorganic gemstones samples obtained by the Fourier Transform Infrared Spectroscopy (FTIR) method, by the Nicolet 6700 Spectrometer (Thermo Electron Corporation), proving the complexity of this consumer relation by requiring technological equipment that is normally accessible to large laboratories, universities and researchers of great practical training and specialized technical knowledge. In this context, the fragility of the consumer is evident due to the essential need for
\end{abstract}

* Professor Doutor da Faculdade de Geologia do Instituto de Geociências da Universidade Federal do Pará e do Programa de Pós-Graduação em Gestão de Riscos e Desastres Naturais da Amazônia (PPGGRD_Amazônia). Advogado. Integrante do grupo de pesquisa "Consumo e Cidadania” (Cnpq).E-mail: mauricio@ufpa.br.

* Professora Doutora do Programa de Pós-Graduação em Geologia e Geoquímica (PPGG) do Instituto de Geociências da Universidade Federal do Pará.E-mail: paz@ufpa.br.

*** Doutor em Direito do Consumidor pela Universidad de Salamanca (Espanha), Mestre em Direito do Consumidor pela Universidade Federal do Pará. Professor da Graduação e dos Programas de Pós-Graduação Stricto Sensu da Universidade Federal do Pará - UFPA e do Centro Universitário do Pará - CESUPA. Procurador do Estado do Pará e Advogado. Líder do grupo de pesquisa “Consumo e Cidadania” (Cnpq).E-mail: dennis@verbicaro.adv.br. 
da necessidade imprescindível da informação, demonstrando que, para haver o equilíbrio das relações entre fornecedores e consumidores atinentes ao comércio de diamantes lapidados e a joalheria a eles associada, perpassa pela aplicação de tecnologias com maior grau de sofisticação para, consequentemente, satisfazer as lacunas informacionais da relação em discussão.

PALAVRAS-CHAVE: Diamantes. Acesso à Informação Qualificada. Liberdade de Escolha do Consumidor. Direito do Consumidor. information, demonstrating that is necessary by the application of technologies with greater degree of sophistication to satisfy the informational gaps.

KEYWORDS: Diamonds. Access to qualified information. Freedom of Consumer Choice. Consumer law.

SUMÁRIO: Introdução. 1. Materiais e Métodos. 2. Os diamantes e a tecnologia usada na sua identificação 3 . Os resultados das análises do caso concreto. 4. A importância da oferta qualificada para o correto exercício da liberdade de escolha do consumidor. Conclusão. Referências.

\section{INTRODUÇÃO}

Uma leitura atenta e refletida do Código de Defesa do Consumidor ${ }^{1}$ (CDC) proporciona de imediato a certeza de que o Sistema Protetivo Consumerista se fundamenta na interdisciplinaridade. Isto é evidente, sobretudo, no elo da cadeia produtiva em que há a destinação final de produtos de alto valor agregado. O conhecimento especializado proveniente de várias áreas é exatamente o que lastreia o comércio seguro, daquele que geralmente é o mais importante de todos os produtos gemológicos, a saber, o diamante lapidado. O consumo desta gema é, fundamentalmente, dependente da informação. Assim, uma parte da tecnologia envolvida na obtenção de dados acerca dos diamantes propriamente ditos constitui o objeto desta investigação.

O estudo detido e a reflexão acerca dos requisitos da oferta previstos no Código de Defesa do Consumidor, em especial a sua aplicabilidade no intuito de servir de parâmetro de controle para o completo esclarecimento aos consumidores do conhecimento tecnológico necessário ao comércio seguro e plenamente esclarecido de itens provenientes dos recursos naturais do meio físico terrestre fomentou o interesse acadêmico e o início de uma cooperação científica com Laboratórios de Pesquisa no Instituto de Geociências da Universidade Federal do Pará, com vistas à investigação pormenorizada destes minerais de gema, bem como as repercussões jurídicas decorrentes de sua comercialização no mercado de consumo.

1 BRASIL. Lei $\mathrm{n}^{\circ}$ 8.078, de 11 de setembro de 1990. Dispõe sobre a proteção do consumidor e dá outras providências. Disponível em: http://www.planalto.gov.br/ccivil_03/leis/18078compilado.htm. Acesso em: 27 mar. 2021. 
Deste modo, o problema que esta pesquisa pretende enfrentar é o da superação da ausência de informações acerca da síntese e tratamentos, as quais são essenciais para o consumo de diamantes lapidados no mercado brasileiro e que podem ter certo nível de esclarecimento, mediante o uso de técnicas espectroscópicas.

Espera-se, também, que os resultados alcançados possam ser usados para garantir o acesso à informação qualificada sobre a natureza, características e respectivo valor agregado de pedras preciosas industrializadas e adquiridas pelo consumidor brasileiro.

Nesta oportunidade são apresentados os resultados da investigação de amostras gemológicas, de diamantes e de simulantes (imitações), todas provenientes do mercado brasileiro. Os espécimes foram investigados por Espectroscopia de Infravermelho Por Transformada de Fourier (FTIR). É mister ressaltar que o Art. 4, III do $\mathrm{CDC}^{2}$ aponta explicitamente a importância do desenvolvimento tecnológico na harmonização das relações de consumo, sobretudo porque vincula, em parte, a proteção do consumidor com aquela referência. Esse é exatamente o contexto no qual os resultados deste trabalho são aplicados e pretendem contribuir com a discussão.

Cabe destacar que, tanto os diamantes sintéticos, quanto aqueles tratados, são de difícil identificação através das técnicas clássicas, utilizadas nos estudos gemológicos (EKGASIT; THONGNOPKUN, 2005)³. Assim, esta investigação tem relevância pela sua aplicação no desenvolvimento da indústria joalheira e na defesa do dever de informar, para o aperfeiçoamento das relações de consumo.

\section{MATERIAIS E MÉTODOS}

São apresentados os resultados provenientes das análises de seis (06) amostras de gemas inorgânicas, obtidas através do método de Espectroscopia de Infravermelho Por Transformada de Fourier (FTIR). O equipamento utilizado foi o Nicolet 6700 Spectrometer (Thermo Electron Corporation).

As amostras investigadas correspondem a quatro (04) diamantes pesando ao redor de 0,1 ct cada e, duas (02) zircônias cúbicas: uma com peso superior a $1 \mathrm{ct}$ e outra ao redor de trinta (30) pontos. Todas as amostras são lapidadas e gemológicas.

Quanto aos diamantes, relata-se, ainda, que foram analisados dois (02) com grau de cor normal e dois (02) corados amarelos.

2 BRASIL. Lei n ${ }^{\circ} 8.078$, de 11 de setembro de 1990. Dispõe sobre a proteção do consumidor e dá outras providências. Disponível em: http://www.planalto.gov.br/ccivil_03/leis/18078compilado.htm. Acesso em: 27 mar. 2021.

3 EKGASIT, Sanong. THONGNOPKUN, Pimthong. Transfletance Spectra of Faceted Diamonds Acquired by Infrared Spectroscopy. Applied Spectroscopy, vol. 59, Issue 9. Sage Journals., pp. 1592-1599, 2005. 
As respostas espectrais foram capturadas através do Software OMNIC (Thermo Electron Corporation), tendo sido reprocessadas através do Software Spectragryph 1.2.8 de Menges (2017) ${ }^{4}$.

Os resultados tiveram a ampliação de seus horizontes de aplicações abstratas através da subsunção dos dispositivos estabelecidos no Código de Defesa do Consumidor.

\section{OS DIAMANTES E A TECNOLOGIA USADA NA SUA IDENTI- FICAÇÃO}

Os diamantes são materiais gemológicos muito especiais e ímpares. Isto se dá primeiramente por serem extremamente raros e essencialmente constituídos, quase que exclusivamente, de Carbono (DANA, 1969) $)^{5}$. Suas propriedades físicas, tais como as resistências à abrasão mecânica, ao uso em vestimenta ("wearing") e à corrosão química; além das características intrínsecas, de natureza cristalofísica, ressaltadas durante a sua lapidação, tais como o brilho, cintilância e fogo ("fire"), o tornam um material de sucesso no uso pela indústria joalheira e, sobretudo, no mercado da moda, propaganda e "marketing”. O "slogan" da De Beers "Os Diamantes São Eternos" é definitivo na vinculação do amor de um casal e a sua desejada perpetuação a uma simbologia de perenidade que só os diamantes possuem.

O diamante, na sua forma lapidada, é um bem de consumo, além de ser uma reserva de valor altamente desejada por grande parte da população no mundo todo, sobretudo por aqueles consumidores dispostos a investir somas consideráveis na sua aquisição. Face da sua importância, o diamante lapidado é a única gema que possui cotação internacional plenamente regulada, com edições semanais, mensais e anuais das suas cotações de preços, através da

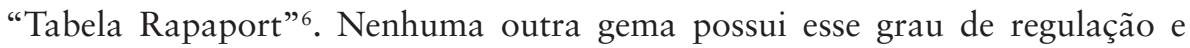
uniformização mundial de preços.

A classificação moderna dos diamantes lapidados foi instituída pelo "Gemological Institute of America" (GIA). Ela é mundialmente aceita nas certificações e estabelecimentos de precificações das relações comerciais intensas que se dão sobre este bem de consumo altamente durável e disputado. Esta classificação norteadora é conhecida como "4 C’s”. Nela, há o necessário enquadramento das "pedras" nos parâmetros de peso ("Carat Weight”), cor

4 MENGES, Friedrich. Spectragryph - Optical Spectroscopy Software. Software Entwicklung. Spectrocopy Ninja, 2017, p. 01. Disponível em: https://www.effemm2.de/spectragryph/index. html. Acesso em: 13 abr. 2018.

5 DANA-HURLBURT JR, C.S. Manual de Mineralogia. $2^{a}$ Edição. Editorial Reverté, S.A. Barcelona. Buenos Aires. México. 1960, p. 247-251.

6 RAPAPORT, M. RAPNET. The Diamond Market. 2019, p. 01. Disponível em: https://info. rapnet.com/diamondtrading. Acesso em: 26 fev. 2019. 
(“Color"), pureza (“Clarity”) e lapidação (“Cut”) (GIA, 2019)7 para que o diamante lapidado, em determinado caso concreto, possa ser avaliado na cadeia de consumo, uma vez que, previamente, estes indicadores (regras de atribuição de valor) estariam organizadamente definidos e precificados.

Contudo, essa subsunção das características do diamante aos parâmetros dos "4 C's", apesar de todos estes serem aparentemente comuns e constituintes da experiência de vida dos consumidores, está muito longe de ser uma tarefa simples.

Apartado desse conhecimento e da tecnologia necessária para verificação dessas informações, o grau de vulnerabilidade do consumidor nas negociações que envolvem esse bem é muito grande, sobretudo se consumido longe dos grandes fornecedores (no geral as tradicionais joalherias do mercado) capazes de afiançar a total garantia. Essa questão ganha relevo, pois existe um mercado "secundário" enorme de diamantes, provenientes de diamantários, joalherias e ourivesarias operando sem esse nível de suporte tecnológico.

Outro aspecto fundamental nessa discussão é a verificação da autenticidade da gema, antes da avaliação dos Parâmetros 4 C's, que se relaciona ao conhecimento intrínseco de que o material que está em tratativas para a obtenção ou que foi obtido pelo consumidor é um diamante natural, ou um diamante tratado, ou um diamante sintético ou, ainda, um simulante.

Claro que todas estas gemas (diamante natural, tratado, sintético ou a imitação/simulante) têm espaço no mercado de consumo. Contudo, o que é imperioso, de fato, é que o consumidor esteja plenamente esclarecido acerca daquilo que está obtendo durante a negociação ou o que obteve quando o consumo aconteceu.

Este trabalho se concentra e discute este primeiro aspecto da relação consumerista dos diamantes lapidados, que constitui o ponto de partida no fornecimento das informações completas e necessárias à compreensão da aquisição que se faz, qual seja, a importância do esclarecimento acerca da natureza do produto a ser consumido, ou seja, se é natural, melhorado, artificial ou imitado. Este ponto também é, hoje, o de maior complexidade tecnológica, pois tais determinações, na maioria das vezes, carecem de acessos a sofisticados e caros equipamentos analíticos, os quais, na quase totalidade, são desconhecidas pelos consumidores, estando somente acessíveis aos grandes laboratórios, Universidades e pesquisadores de grande treinamento prático e especializado conhecimento técnico.

Uma pequena noção desse problema é que os próprios diamantários enfrentam mais e mais a aquisição indesejada de "partidas" de "pedras", algumas vezes habilmente "montadas" (ditas "batizadas” no jargão geológico)

7 GIA. Gemological Institute of America. 4Cs Of Diamond Quality. 2019, pp. 01-02. Disponível em: https://4cs.gia.edu/en-us/4cs-diamond-quality/. Acesso em: 26 fev. 2019. 
de maneira a serem constituídas de um "mix" de diamantes naturais e diamantes sintéticos (KRAWITZ, 2019).

Neste trabalho, as amostras investigadas foram avaliadas usando a Espectroscopia de Infravermelho Por Transformada de Fourier (FTIR). O uso da tecnologia de interferometria utilizando Transformadas de Fourier, além de possibilitar a extensão das faixas espectrais de investigação vibracional, possibilita a obtenção mais rápida de dados (SALA, 1996) ${ }^{9}$. O intervalo que se priorizou nesse trabalho foi a investigação da absorção da radiação no infravermelho Médio entre $400 \mathrm{~cm}^{-1}$ a $4.000 \mathrm{~cm}^{-1}$.

Apesar da descoberta da radiação infravermelha ter se dado há mais de dois séculos, por Herschel, em 1800 (SALA, 1996) ${ }^{10}$, somente em tempos mais recentes é que esta tem sido utilizada de forma intensiva, em estudos gemológicos de diamantes (LOWRY, 2007; LANG, ET AL, 2007; CLARK, ET AL., 1979) ${ }^{11}$, através da avaliação da radiação eletromagnética infravermelha com o material no estado sólido. A investigação por Espectroscopia de Infravermelho Por Transformada de Fourier visa perquirir a estrutura molecular, os níveis de energia e as ligações dos vários compostos químicos (SALA, 1996) ${ }^{12}$, para os quais a técnica enfatiza a avaliação das regiões espectrais dependentes, neste caso, dos níveis vibracionais; considerando-se que a energia total da molécula é a soma das energias eletrônica, vibracional e rotacional de acordo com a expressão " $\mathrm{E}_{\text {tot }}=\mathrm{E}_{\text {ele }}+\mathrm{E}_{\mathrm{vib}}+\mathrm{E}_{\text {rot" }}(\text { Compilada de SALA, 1996) })^{13}$.

Destaca-se que estes níveis podem ser estudados separadamente, que é o que se faz na Espectroscopia por Infravermelho Por Transformada de Fourier para este caso concreto, onde a ênfase é posta na avaliação das vibrações moleculares presentes nos diamantes e simulantes através dos espectros vibracionais obtidos.

8 KRAWITZ, Avi. Synthetics: The Meat of The Matter. Polished Markets. RAPAPORT. 2019, pp. 01-02. Diamonds.Net, 21 de Fevereiro de 2019. Disponível em: https:/www.diamonds.net/ News/NewsItem.aspx?ArticleID=63390\&ArticleTitle=Synthetics $\% 3 \mathrm{~A}+$ The + Meat + of + the $+\mathrm{M}$ atter+. Acesso em 25 fev. 2019.

9 SALA, Oswaldo. Fundamentos da Espectroscopia Raman e no Infravermelho. SP: Unesp, 1996, p. 16.

10 Ibidem, p. 14.

11 LOWRY, Stephen. Analysis of Diamonds by FT-IR Spectroscopy. Sprectroscopy, v. 22. Issue, 2007, p. 03.

LANG, A.R.; BULANOVA, G.P.; FISCHER, D.; FURKERT, S.; SARUA, A. Defects in a mixhabit Yakutian diamond: Studies by optical and cathodoluminescence, infrared absortion, Raman scattering and photoluminescence spectroscopy. Journal of Crystal Growth, v. 309, 2007, p. 174.

CLARK, C. D.; MITCHELL, E.W.J.; PARSONS, B.J. Color Centres and Optical Properties. In: The properties of Diamond. Chapter 2. FIELD, J.E. Editor. London. Academic Press. 1979, p. 23-77.

12 SALA, Oswaldo. Fundamentos da Espectroscopia Raman e no Infravermelho. SP: Unesp. 1996, p. 17.

13 Ibidem, p. 14. 
O que se deve ponderar nesse tipo de investigação, segundo Sala $(1996)^{12}$ é que

A absorção no infravermelho ocorre quando a frequência de radiação, multiplicada pela Constante de Planck, tem o mesmo valor da diferença de energia entre dois estados vibracionais, ou seja, o processo envolve uma ressonância entre a diferença de níveis de energia da molécula e a radiação eletromagnética (SALA, 1996) ${ }^{14}$.

Outro ponto relevante, segundo o autor supra, é que “(...) para um modo vibracional ser atingido no infravermelho é necessário que haja variação do momento dipolar durante essa vibração" (SALA, 1996) ${ }^{15}$.

Assim, nos cristais dielétricos, a transmissão de energia vibracional conduz calor, manifestada pelo fluxo de "phonons", o que influenciará, também, na condutividade térmica dos diamantes (BERMAN, 1979)16. A propriedade de condutividade térmica dos diamantes é bem conhecida e muito investigada pela indústria de equipamentos para joalheria, no sentido de se produzirem máquinas de baixo custo no mercado visando a detecção de simulantes e a identificação de diamantes genuínos. São exemplos os produtos da Presidium, da Smartpro, dentre outros. Esta abordagem, embora tecnologicamente simples, não será abordada neste trabalho.

Do ponto de vista da Espectroscopia de Infravermelho, a análise dos diamantes favorece o alcance dos espectros, que podem ser entendidos como "índexes", permitindo, com segurança, identificar a autenticidade dos diamantes lapidados, quando investigados. Isso se torna extremamente relevante, pois permite a avaliação do material gemológico, quando o mesmo já se encontra industrializado, ou seja, após ter sido lapidado, quando as possíveis indicações de superfície foram todas praticamente removidas, dificultando a sua identificação pelos métodos usuais de análise morfológica dos cristais, conhecidos como “brutos”. Outrossim, é exatamente neste ponto, ou seja, em seu estado lapidado ("cutted") que o consumidor final, na quase absoluta totalidade efetiva, de forma terminativa, a relação de consumo. Com base nestas últimas afirmações, é evidente a fragilidade do consumidor final em função da necessidade imprescindível da informação - que, neste contexto, é muito especializada.

O fundamento da avaliação de diamantes pela técnica de Espectroscopia de Infravermelho baseia-se no fato de que, a despeito desta gema possuir uma estrutura interna cristalina, estabelecida no arranjo quase exclusivo de tetraédros de Carbono, esta mesma estrutura retém uma série de outros elementos traços, sendo o Nitrogênio e o Boro os mais importantes para fins de classificação,

14 Ibidem, p. 15.

15 Ibidem, p. 15.

16 BERMAN, R. Thermal Properties. The properties of Diamond. Chapter 1. FIELD, J.E. Editor. London: Academic Press, 1979, p. 3-22. 
embora vários outros existam (LOWRY, 2007; DEL REY, 2002) ${ }^{17}$. A maneira pela qual o primeiro se apresenta e se organiza na estrutura do diamante é definitiva para o estabelecimento das várias tipologias existentes (SHIGLEY, $2016)^{18}$. A presença desses elementos traços produzem assinaturas espectrais no Infravermelho, em padrões que permitem sua vinculação ao diamante, constituindo, assim, um eficaz meio de determinação.

Uma importante discussão que deriva do atual estado de arte da técnica é a possibilidade de mensuração e limitações da mesma no entendimento dos processos de síntese e "melhoramentos" de diamantes.

\section{OS RESULTADOS DAS ANÁLISES DOS CASOS CONCRETOS}

A Figura 01 apresenta as quatro distribuições espectrais, na banda do infravermelho médio $\left(400 \mathrm{~cm}^{-1}\right.$ a $4.000 \mathrm{~cm}^{-1}$, com resolução de $\left.2 \mathrm{~cm}^{-1}\right)$ para diamantes lapidados, as quais foram alocadas em único "plot", para fins de comparação. Para os diamantes gemológicos, a técnica foi usada através do Método da Reflectância Difusa, com a incidência da radiação eletromagnética se dando com os espécimes tendo seus pavilhões imersos nas pastilhas de $\mathrm{KBr}$. Assim, o que se apresenta são resultados exclusivos das absorções manifestadas pela mesa dos espécimes.

Destaca-se que os resultados foram representativos mesmo para amostras de dimensões tão diminutas. Cabe destacar a baixa verticalização e a tendência ao aplanamento do padrão espectral do diamante AM-31. Contudo, todos os espécimes mostraram respostas vibracionais, que podem ser perfeitamente correlacionadas àquelas encontradas nos diamantes naturais do Tipo I (CLARK et al., 1979 $)^{19}$, que representam a variedade dominante.

Todos os gráficos registraram atividades vibracionais nos fônons do Nitrogênio e do Hidrogênio, além daquele intrínseco do diamante.

17 LOWRY, Stephen. Analysis of Diamonds by FT-IR Spectroscopy. Sprectroscopy, v.22. Issue, 2007, p. 01.

DEL REY, Mario. Como Comprar e Vender Diamantes. Editora Ao Livro Técnico. Rio de Janeiro, 2002, p. 21.

18 SHIGLEY, J.E. Identifying Lab-Grown Diamonds. Research \& News. GIA. July 25, 2016, p. 02. Disponível em: https://www.gia.edu/identifying-lab-grown-diamonds. Acesso em 28 fev. 2019.

19 CLARK, C. D.; MITCHELL, E.W.J.; PARSONS, B.J. Color Centres and Optical Properties. In: The properties of Diamond. Chapter 2. FIELD, J.E. Editor. London: Academic Press, 1979, p. 26. 


\section{FIGURA 01}

Padrões espectrais no Infravermelho Médio, para quatro amostras de diamantes lapidados do mercado brasileiro. O eixo das abcissas é corresponde aos "números de onda", expressos em $\mathrm{cm}^{-1} \mathrm{e}$, o eixo das ordenadas indica os valores de absorbância da radiação infravermelha.

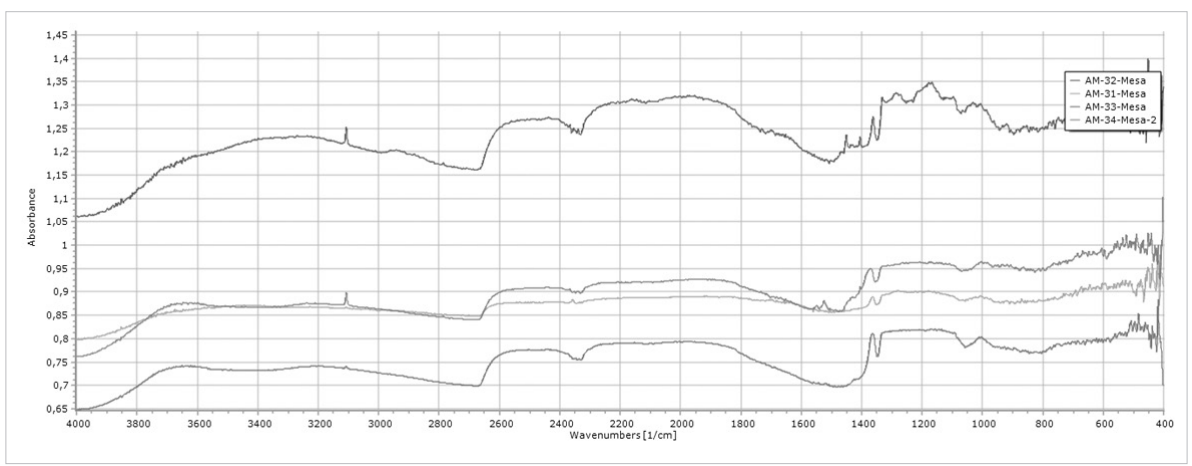

Fonte: Autores.

$\mathrm{Na}$ avaliação coletiva dos espectros de Infravermelho obtidos, destaca-se o intervalo dos números de onda entre $900 \mathrm{~cm}^{-1}$ e $1.500 \mathrm{~cm}^{-1}$. Neste, é notório o registro da presença dos átomos de Nitrogênio ocupando espaços intersticiais da estrutura interna cristalina do diamante, deixados pela ausência de átomos de Carbono. Isto pode ser identificado pela presença das bandas de absorção bem definidas.

O diamante AM-32-Mesa mostra uma disposição de bandas de absorção diversa das amostras subsequentes. É possível que exista a indicação de centros de ativação diferentes na estrutura interna cristalina do mineral. $\mathrm{O}$ espectro mencionado é muito similar àqueles encontrados para diamantes com atividades em "Centros B", o qual é composto por quatro átomos de Nitrogênio distribuídos ao redor de uma vacância estrutural (CAVALLARO, 2008) ${ }^{20}$.

Uma consideração que deve ser indicada é que todas as amostras exibem banda de absorção destacada na altura do número de onda $1.370 \mathrm{~cm}$ 1, a qual deve se relacionar à presença de estruturas internas na nanoescala, provavelmente relacionadas aos "platelets".

Outrossim, é que os espectros exibidos pelas amostras 32-Mesa, 33-Mesa e 34-Mesa-2 apresentaram destacada banda de absorção na região do número de onda $3.107 \mathrm{~cm}^{-1}$, indicando a presença de traços de Hidrogênio na estrutura destes diamantes.

20 CAVAllarO, Tatiana Ruiz. Caracterização Física, Mineralógica e Gemológica de Diamantes Coloridos da Coleção do Museu de Geociências. Dissertação de Mestrado. Programa de Pós-Graduação em Mineralogia e Petrologia. USP. SP. 2008, p. 65. 
Desta forma, a confiabilidade destes quatro (04) produtos gemológicos quanto à autenticidade é muito elevada, tendendo a serem descartados quaisquer processos de síntese e de possíveis tratamentos. Esse tipo de resultado é essencial, pois repercute no preço e, também, na boa-fé objetiva e na lealdade contratual. A boa-fé objetiva é uma das preocupações diretas do controle pré-contratual do CDC e constitui uma referência axiológica importante para o sistema protetivo consumerista como um todo.

A Figura 02 representa o espectro de Infravermelho Médio, utilizandose do Método da Reflexão Total Atenuada (ATR) que foi obtido a partir da Amostra S-01-ATR e trata da assinatura para a zircônia cúbica $(\mathrm{ZrO} 2)$, que é muito utilizada na joalheria moderna em substituição ao diamante natural.

A Figura 03 representa o espectro de Infravermelho Médio, obtido através do Método da Reflectância Difusa para a Amostra S-03-Mesa e, igualmente, representa a assinatura da zircônia cúbica $(\mathrm{ZrO} 2)$.

\section{FIGURA 02}

Assinatura da Amostra S-01-ATR de zircônia cúbica ( $\mathrm{ZrO} 2)$ no espectro de radiação infravermelho sob a Técnica de ATR. O eixo " $X$ " corresponde aos números de onda e, o eixo" Y “, aos valores de absorbância da radiação Infravermelha.

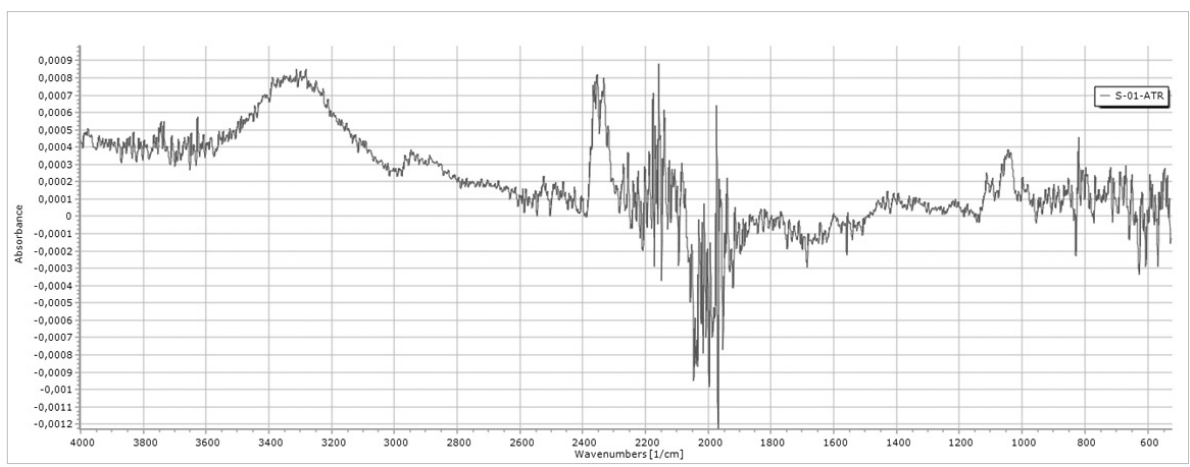

Fonte: Autores.

\section{FIGURA 03}

Assinatura da Amostra S-03-Mesa de zircônia cúbica ( $\mathrm{ZrO} 2)$ no espectro de radiação infravermelho sob a Técnica de Refletância Difusa. O eixo "X" corresponde aos números de onda e, o eixo" $\mathrm{Y}$ ", aos valores de absorbância da radiação Infravermelha. É notória a absorção a altura do número de onda 800 $\mathrm{cm}^{-1}$, além de picos menores dispostos entre $2.330 \mathrm{~cm}^{-1} \mathrm{e} 2.660 \mathrm{~cm}^{-1}$. 


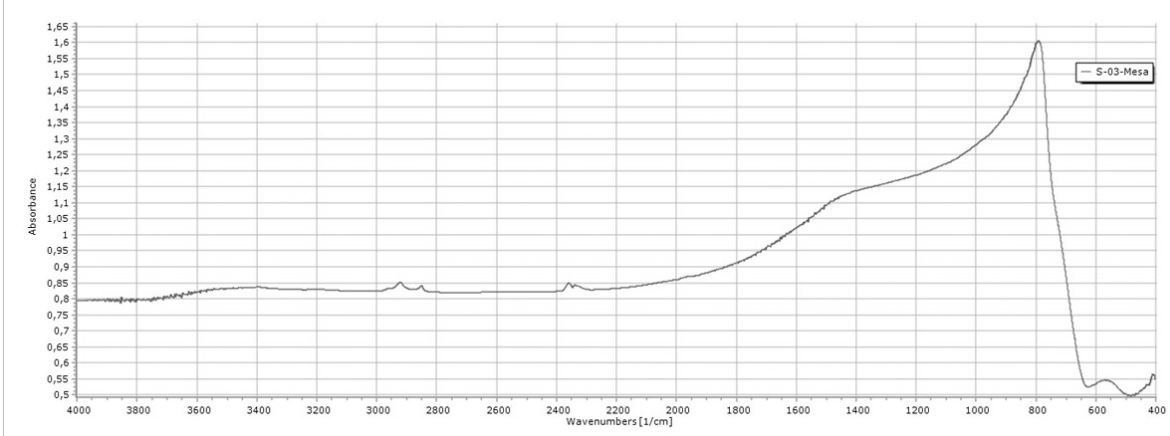

Fonte: Autores.

As diferenças de geometrias dos gráficos das zircônias cúbicas, das Figuras 02 e 03, são notórias com relação àquelas esperadas para os espectros dos diamantes naturais e, deste modo, em nada se confundem com as distribuições anteriores, apresentadas na Figura 01. Assim, a identificação da zircônia cúbica, quando comparada espectralmente aos diamantes, torna-se muito facilitada através da aplicação do Método da Refletância Difusa de FTIR.

Uma avaliação detida dos espectrogramas obtidos aponta para a constatação de que a análise dos diamantes lapidadados, pelo Método de ATR, não representa uma boa alternativa, devendo, portanto, ser evitada.

Por outro lado, as análises efetivadas através do Método da Reflectância Difusa produzem resultados excelentes.

\section{A IMPORTÂNCIA DA OFERTA QUALIFICADA PARA O COR- RETO EXERCÍCIO DA LIBERDADE DE ESCOLHA DO CON- SUMIDOR.}

De acordo com o estabelecido no art. 31 do Código de Defesa do Consumidor ${ }^{21}$, a "oferta e apresentação de produtos ou serviços devem assegurar informações corretas, claras, precisas, ostensivas e em língua portuguesa sobre suas características, qualidades, quantidade, composição, preço, garantia, prazos de validade e origem, entre outros dados" (...). Este dispositivo assegura que as ofertas de diamantes lapidados, no mercado consumidor brasileiro, devem ser antecedidas e acompanhadas de informações exatas, com o maior grau de perfeição possível. Ressalta-se que, muito embora o dispositivo cuide da questão no nível pré-contratual, não descura também de que as mesmas informações e cuidados devam ser prestados durante o aperfeiçoamento e acabamento do contrato de consumo (MARQUES, 2006) ${ }^{22}$.

21 BRASIL. Lei n ${ }^{\circ} 8.078$, de 11 de setembro de 1990. Dispõe sobre a proteção do consumidor e dá outras providências. Disponível em: http://www.planalto.gov.br/ccivil_03/leis/18078compilado.htm. Acesso em: 27 mar. 2021.

22 MARQUES, Claudia Lima. Contratos no Código de Defesa do Consumidor: O Novo Regime 
A informação, hoje, é vista como valor e mecanismo de controle por parte dos fornecedores, que conseguem adaptar seus mercados e áreas de influência à sociedade do consumo. Nesse sentido, a proteção legal da oferta na seara consumerista assume a responsabilidade de influir na própria obrigatoriedade da oferta, pois a ideia de vinculação pré-contratual será condicionada pelo dever de informação. A obrigatoriedade recai não sobre a oferta em si, mas sobre o próprio dever de informação, que não deverá ter como resultado a expressão unilateral de vontade do fornecedor ou mesmo a omissão acidental ou proposital de informações relevantes acerca das características, valor agregado dos produtos, sobretudo aqueles associados à ideia de exclusividade $\mathrm{e}$ ostentação, como é o caso dos diamantes.

No atual contexto das relações de consumo, em que as necessidades artificiais assumiram um maior protagonismo que as existenciais (fisiológicas), o consumo hedonista do prazer pelas experiências exclusivas e o desejo pela aceitação social através da ostentação impõem um novo padrão comportamental ao consumidor. Essa mudança social nos hábitos de consumo ganha especial destaque quando se trata de um produto de elevado valor agregado e que habita o imaginário desse consumidor hipermoderno, como é o caso dos diamantes.

$\mathrm{O}$ acesso à informação, por sua vez, é o ponto de partida para o próprio exercício da liberdade de escolha, define os conceitos de vício e defeito na responsabilidade civil, além de ser revelar aspecto determinante para caracterização da oferta e publicidade ilícitas.

Nesse sentido, a proteção necessária ao consumidor impõe uma nova roupagem à oferta, garantindo-se um consentimento refletido e uma escolha bem fundada. Não se pode fugir à realidade de que o dever de informação é determinante para o sucesso do negócio jurídico e importante mecanismo de prevenção de conflitos de consumo, não apenas para o consumidor, como também para o fornecedor que, ao agir de modo transparente, favorece a criação de uma identidade como aquele, fidelizando o, algo fundamental para se manter relevante num mercado competitivo.

Como exemplos muito representativos da importância deste fato, encontram-se as indicações acerca das possibilidades de síntese, de tratamentos e, algumas vezes de simulação destas gemas. Os espécimes sintéticos têm amplificado as suas participações no mercado consumidor nos últimos anos. Neste contexto, a declaração contida no trabalho de Krawit $(2019)^{23}$ é muito emblemática:

das Relações Contratuais. $5^{\text {a }}$. Edição. Instituto Brasileiro de Política e Direito do Consumidor. Biblioteca de Direito do Consumidor - 1. São Paulo: Revista dos Tribunais, 2006, p. 771.

23 KRAWITZ, Avi. Synthetics: The Meat of The Matter. Polished Markets. RAPAPORT. Diamonds.Net, 21 de Fevereiro de 2019. Disponível em: https://www.diamonds.net/News/NewsItem. aspx?ArticleID=63390\&ArticleTitle=Synthetics\%3A+The+Meat + of + the + Matter + . Acesso em 
For us, 2018 was the year that lab-grown Diamonds got a place in the jewelry industry', researchers at lender ABN Amro wrote in a recente report. 'We think that 2019 and 2020 will be the years that lab-grown Diamonds take off and move from na introduction phase to a growth phase. (KRAWITZ, $2019)^{20}$.

O acesso à informação clara, precisa e direcionada é o maior problema dos consumidores no que concerne ao acesso seguro e consciente aos diamantes lapidados no mercado de consumo, em especial quando se fala em termos de mercado secundário e daqueles oriundos das pequenas joalherias e até de médios produtores e do comércio pela “internet”. Esta dificuldade é tão grande que supera até mesmo a questão do preço propriamente dito. Assim, fora das grandes joalherias ou dos grandes fornecedores de diamantes lapidados, a obtenção de informações indubitáveis e relevantes, como prescreve o art. 31 $\mathrm{CDC}^{24}$, é muito difícil.

As características exatas e, sobretudo suas qualidades e composições, dentre outras, só podem ser obtidas a partir do uso intensivo de tecnologia, a qual não está disponível aos pequenos e médios produtores. Com base nisso, é perceptível a desvantagem contratual, a qual está naturalmente submetida o consumidor em uma relação de consumo envolvendo estes bens.

A necessidade de informação, bem como a sua garantia, nas relações de consumo, sobretudo nestes entendidos como complexos, é tão patente, que alguns autores reforçam que seus contornos encontram-se seguramente albergados no bojo do Direito Constitucional (MIRAGEM; BERGSTEIN, 2017)25.

É obvio que, o que se está a resguardar mais que tudo, no mandamento do art. $31 \mathrm{CDC}^{26}$, é o princípio da transparência, que é também previsto em seu art. $4^{\circ}$. Segundo Marques (2006, p. 771)27, “é maior clareza, é veracidade e respeito, através de maior troca de informações entre o fornecedor e o consumidor na fase pré-contratual. Contudo, não se deve olvidar, que "pari passu” a este se encontra o Princípio da Boa-Fé Objetiva”.

25 fev. 2019, p. 2.

24 BRASIL. Lei n ${ }^{\circ} 8.078$, de 11 de setembro de 1990. Dispõe sobre a proteção do consumidor e dá outras providências. Disponível em: http://www.planalto.gov.br/ccivil_03/leis/18078compilado.htm. Acesso em: 27 mar. 2021.

25 MIRAGEM, Bruno. BERGSTEIN, Lais. O Papel da Informação nos Contratos de Consumo Como Modelo do Novo Direito Privado Solidário. In: VERBICARO, Dennis; ATAÍDE, Camille; ACIOLI, Carlos. (Eds). Provocações Contemporâneas no Direito do Consumidor. Editora Lumen Juris Direito. Rio de Janeiro, 2018.

26 BRASIL. Lei n ${ }^{\circ} 8.078$, de 11 de setembro de 1990. Dispõe sobre a proteção do consumidor e dá outras providências. Disponível em: http://www.planalto.gov.br/ccivil_03/leis/18078compilado.htm. Acesso em: 27 mar. 2021.

27 MARQUES, Claudia Lima. Contratos no Código de Defesa do Consumidor: O Novo Regime das Relações Contratuais. $5^{\text {a }}$. Edição. Instituto Brasileiro de Política e Direito do Consumidor. Biblioteca de Direito do Consumidor - 1. São Paulo: Revista dos Tribunais, 2006, p. 771. 
Assim, apresentar todas as informações essenciais ao conhecimento da natureza dos diamantes lapidados que se está fornecendo representa o fundamento de toda a estrutura contratual que se apresenta e o cerne da transparência. Onde as informações essenciais e precisas ao esclarecimento completo do consumidor estão ausentes, a transparência resta comprometida e, portanto, a boa-fé objetiva segue o mesmo curso:

O dispositivo tem, na sua origem, o princípio da transparência, previsto expressamente pelo CDC $\left(\operatorname{art.} 4^{\circ}\right.$, caput). Por outro lado, é decorrência também do princípio da boa-fé objetiva, que perece em ambiente onde falta a informação plena ao consumidor (GRINOVER et al., 2000) ${ }^{28}$.

Em trabalho recente, ressaltando a importância dessa questão, Verbicaro $(2017)^{29}$ nos aponta que:

A boa-fé é uma via de mão dupla, ou seja, pressupõe deveres recíprocos entre o consumidor e o fornecedor e será o ponto de partida para outros direitos básicos consagrados no CDC, como o acesso à informação qualificada e própria preservação da liberdade de escolha do consumidor.

Desta forma, o equilíbrio necessário nas relações de consumo, envolvido na tradição de um item tão raro e valioso, como o que se dá na aquisição de diamantes lapidados, perpassa, obrigatoriamente, pela questão tecnológica.

Uma discussão que se torna possível, mas que se expandiria para além do escopo deste trabalho, seria aquela decorrente das seguintes ponderações: 1) Se, para os pequenos e médios fornecedores, a quem cabe o dever de informar $(\text { MARQUES, 2006) })^{30}$, a tecnologia necessária para a aquisição de uma base de dados coroada de certeza, está fora do seu alcance imediato, o que dizer da consequência na liberdade de escolha dos consumidores de diamantes lapidados, que obviamente são os hipossuficientes?; 2) Qual a estratégia a ser aplicada para permitir a superação dessa barreira ao consumo seguro?

\section{CONCLUSÕES}

Com base nas atividades de pesquisas tecnológicas empreendidas neste trabalho, as quais se materializaram na obtenção dos espectros de infravermelho (FTIR) de diamantes lapidados, concluiu-se que estas agregam confiabilidade

28 GRINOVER, Ada Pellegrini; BENJAMIN, Antônio Herman de Vasconcelos e; FINK, Daniel Roberto; FILOMENO, José Geraldo Brito; WATANABE, Kazuo; NERY JÚNIOR, Nelson; DENARI, Zelmo. Código Brasileiro de Defesa do Consumidor comentado pelos autores do anteprojeto. 6. ed. Rio de Janeiro: Forense Universitária, 2000, p. 284.

29 VERBICARO, Dennis. Consumo e Cidadania: Identificando os espaços políticos de atuação qualificada do consumidor. Rio de Janeiro, Editora Lumen Juris, 2017, p. 215.

30 MARQUES, Claudia Lima. Contratos no Código de Defesa do Consumidor: O Novo Regime das Relações Contratuais. $5^{\text {a }}$. Edição. Instituto Brasileiro de Política e Direito do Consumidor. Biblioteca de Direito do Consumidor - 1. São Paulo: Revista dos Tribunais, 2006, p. 771. 
às relações de consumo e, nos dias de hoje, são essenciais para a garantia do princípio da transparência, como da própria liberdade de escolha do consumidor.

O método foi eficiente para espécimes de dimensões diminutas, com cerca de dez (10) centésimos de quilate, cada. Houve perfeita separação de espectros entre os diamantes naturais e a sua imitação mais usual, que é a zircônia cúbica.

Como consequência imediata, tem-se o entendimento de que o acesso à informação precisa sobre as características, natureza e real valor agregado do produto não apenas qualifica a oferta, atinge a exigência da veracidade, como também favorece o equilíbrio das relações entre fornecedores e consumidores atinentes ao comércio de diamantes lapidados e a joalheria a eles associada, tudo através da aplicação de tecnologias com maior grau de sofisticação.

Assim, a pesquisa demonstrou que as relações de consumo voltadas à aquisição de diamantes lapidados soltos e a joalheria derivada, no momento, são dependentes das análises laboratoriais caras e de difícil acesso, o que coloca o consumidor numa posição de vulnerabilidade agravada, pois dependerá exclusivamente da certificação interna da marca sobre a autenticidade do produto adquirido, o que, dependendo do caso e pelas mesmas dificuldades supra, impeça o próprio comerciante de fazê-lo.

\section{REFERÊNCIAS}

BERMAN, R. Thermal Properties. The properties of Diamond. Chapter 1. FIELD, J.E. Editor. London: Academic Press, 1979, p. 3-22.

BRASIL. Lei $n^{\circ}$ 8.078, de 11 de setembro de 1990. Dispõe sobre a proteção do consumidor e dá outras providências. Disponível em: http://www.planalto.gov. br/ccivil_03/leis/18078compilado.htm. Acesso em: 27 mar. 2021.

CAVALLARO, Tatiana Ruiz. Caracterização Física, Mineralógica e Gemológica de Diamantes Coloridos da Coleção do Museu de Geociências. Dissertação de Mestrado. Programa de Pós-Graduação em Mineralogia e Petrologia. USP. SP. 2008.

CLARK, C. D.; MITCHELL, E.W.J.; PARSONS, B.J. Color Centres and Optical Properties. In: The properties of Diamond. Chapter 2. FIELD, J.E. Editor. London: Academic Press. 1979, p. 23-77.

DE BEERS GROUP. The Group. 2019. Disponível em: https://www.debeersgroup.com/the-group/about-debeers-group/brands/a-diamond-is-forever. Acesso em: 27 fev. 2019.

DANA-HURLBURT JR, C.S. Manual de Mineralogia, Vol. I e II - Ao livro Técnico USP, Rio de Janeiro (Trad. Rui Ribeiro Franco), 1969.

DEL REY, Mario. Como Comprar e Vender Diamantes. Editora Ao Livro Técnico. Rio de Janeiro, 2002. 
DENARI, Zelmo. Código Brasileiro de Defesa do Consumidor: Comentado Pelos Autores do Anteprojeto. $9^{a}$ Edição. Revista, atualizada e ampliada. Rio de Janeiro: Forense Universitária, 2007.

EKGASIT, Sanong. THONGNOPKUN, Pimthong. Transfletance Spectra of Faceted Diamonds Acquired by Infrared Spectroscopy. Applied Spectroscopy, Vol. 59, Issue 9. Sage Journal, 2005.

GIA. Gemological Institute of America. 4Cs of Diamond Quality. Disponível em: https://4cs.gia.edu/en-us/4cs-diamond-quality/. Acesso em: 26 fev. 2019.

GRINOVER, Ada Pellegrini; BENJAMIN, Antônio Herman de Vasconcelos e; FINK, Daniel Roberto; FILOMENO, José Geraldo Brito; WATANABE, Kazuo; NERY JÚNIOR, Nelson; DENARI, Zelmo. Código Brasileiro de Defesa do Consumidor comentado pelos autores do anteprojeto. 6. ed. Rio de Janeiro: Forense Universitária, 2000.

KRAWITZ, Avi. Synthetics: The Meat of The Matter. Polished Markets. RAPAPORT. Diamonds.Net, 21 de Fevereiro de 2019. Disponível em: https://www. diamonds.net/News/NewsItem.aspx? ArticleID=63390\&ArticleTitle=Synthetics\%3A+The+Meat+of+the+Matter+. Acesso em 25 fev. 2019.

LANG, A.R.; BULANOVA, G.P.; FISCHER, D.; FURKERT, S.; SARUA, A. Defects in a mix-habit Yakutian diamond: Studies by optical and cathodoluminescence, infrared absortion, Raman scattering and photoluminescence spectroscopy. Journal of Crystal Growth, v. 309, 2007.

LOWRY, Stephen. Analysis of Diamonds by FT-IR Spectroscopy. Sprectroscopy, v.22. Issue, 2007.

MARQUES, Claudia Lima. Contratos no Código de Defesa do Consumidor: O Novo Regime das Relações Contratuais. $5^{\text {a }}$. Edição. Instituto Brasileiro de Política e Direito do Consumidor. Biblioteca de Direito do Consumidor - 1. São Paulo: Revista dos Tribunais, 2006.

MENGES, Friedrich. Spectragryph - Optical Spectroscopy Software. Software Entwicklung. Spectrocopy Ninja, 2017. Disponível em: https://www.effemm2. de/spectragryph/index.html. Acesso em: 13 abr. 2018.

MIRAGEM, Bruno. BERGSTEIN, Lais. O Papel da Informação nos Contratos de Consumo Como Modelo do Novo Direito Privado Solidário. In: VERBICARO, Dennis; ATAÍDE, Camille; ACIOLI, Carlos. (Eds). Provocações Contemporâneas no Direito do Consumidor. Editora Lumen Juris Direito. Rio de Janeiro, 2018.

NERY, Miguel Antônio Cedraz e HENRIQUÈS, Hécliton Santini. Boletim Referencial de Preços de Diamantes e Gemas de Cor. $5^{\text {a }}$ Edição - Revisada e Ampliada. Convênio DNPM/IBGM. Brasília (DF), 2005. 
RAPAPORT, M. RAPNET. The Diamond Market. Disponível em: https://info. rapnet.com/diamondtrading. Acesso em: 26 fev. 2019.

SALA, Oswaldo. Fundamentos da Espectroscopia Raman e no Infravermelho. SP: Unesp. 1996.

SHIGLEY, J.E. Identifying Lab-Grown Diamonds. Research \& News. GIA. July 25, 2016. Disponível em: https://www.gia.edu/identifying-lab-grown-diamonds. Acesso em: 28 fev. 2019.

VERBICARO, Dennis. Consumo e Cidadania: Identificando os espaços políticos de atuação qualificada do consumidor. Rio de Janeiro, Editora Lumen Juris, 2017.

Os autores agradecem ao Laboratório de Caracterização Mineral (LCM) Setor Análises, do Programa de Pós-Graduação em Geologia e Geoquímica do Instituto de Geociências da Universidade Federal do Pará (CPGG-UFPA), pelo fornecimento de toda a infraestrutura de preparação e análise para Espectroscopia de Infravermelho Por Transformada de Fourier (FTIR), que proporcionou a obtenção dos Espectros IV, para as amostras investigadas. Nesta oportunidade os agradecimentos são estendidos ao Geólogo MSc. Alan Rodrigo Leal de Albuquerque, pelo auxílio na preparação de amostras, e na coleta de dados FTIR no Espectrômetro Nicolet 6700. Os Autores também são gratos ao Dr. Friedrich Menges do "The Spectroscopy Ninja (Germany)" pela cessão de uso e "free download" do "Software Spectragryph Version 1.2.8".

Recebido em: 15/04/2020.

Aprovado em: 29/03/2021. 
